\title{
Temporary epicardial left ventricular and biventricular pacing improves cardiac output after cardiopulmonary bypass
}

Jose B García-Bengochea ${ }^{1 *}$, Angel L Fernández', Daniel Sánchez Calvelo', Julian Alvarez Escudero², Francisco Gude 3 and José R González Juanatey ${ }^{4}$

\begin{abstract}
Background: To evaluate, with different pacing modes, acute changes in left ventricular systolic function, obtained by continuous cardiac output thermodilution in various subsets of patients undergoing cardiopulmonary bypass surgery. Increments of mean arterial pressure and cardiac output were considered the end point.

Methods: Fifty cases electively submitted to cardiac surgery were analyzed. Isolated valve surgery $62 \%$, coronary revascularization 30\% and $8 \%$ mixed disease. Left ventricular ejection fraction was preserved in 50\%,36\% had moderate depression,(EF 36\%-50\%) whereas 14\% had severe depression (EF < 35\%). Left bundle branch block occurred in $18 \%$. Preoperatively $84 \%$ were in sinus rhythm and $16 \%$ in atrial fibrillation. The different subgroups were analyzed for comparisons. Right atrial-right ventricular and right atrial-left ventricular pacing were employed in sinus rhytm. Biventricular pacing was also used in atrial fibrillation.

Results: Right atrium-right ventricular pacing, decreased significantly mean arterial pressure and cardiac output $(2.3 \%)$ in the overall population and in the subgroups studied. Right atrium-left ventricle, increased mean arterial pressure and cardiac output in $79 \%$ of patients and yielded cardiac output increments of $7.5 \%(0.40 \mathrm{l} / \mathrm{m})$ in the low ejection fraction subgroup and $7.3 \%(0.43 \mathrm{l} / \mathrm{m})$ in the left bundle branch block subset. In atrial fibrillation patients, left ventricular and biventricular pacing produced a significant increase in cardiac output $8.5 \%(0.39 \mathrm{l} / \mathrm{min})$ and $11.6 \%(0.53 \mathrm{l} / \mathrm{min})$ respectively. The $\mathrm{dP} / \mathrm{dt}$ max increased significantly with both modes $(p=0.021, p=0.028)$.

Conclusion: Right atrial-right ventricular pacing generated adverse hemodynamic effects. Right atrium-left ventricular pacing produced significant CO improvement particularly in cases with depressed ventricular function and left bundle branch block. The greatest increments were observed with left ventricular or biventricular pacing in atrial fibrillation with depressed ejection fraction.
\end{abstract}

Keywords: Postoperative cardiac pacing, Left ventricular, Biventricular, Cardiac output optimization, Atrial fibrillation

\section{Background}

The benefits of cardiac re-synchronization therapy (CRT) in chronic heart failure with severe left ventricular (LV) dysfunction due to ventricular dyssynchrony have been established by several randomized controlled trials [1-3], demonstrating that the use of left ventricular pacing (LVP) or biventricular (BiVP)) pacing improves cardiac function by generating a more efficient ventricular

\footnotetext{
* Correspondence: alfg@secardiologia.es

${ }^{1}$ Cardiac Surgical Division. Department of Surgery, Hospital Clínico

Universitario, 15706, Santiago de Compostela, Spain

Full list of author information is available at the end of the article
}

contraction. Besides, deleterious effects of chronic right ventricular (RV) apical pacing on LV performance have been reported [4].

Cardiac function is often diminished after cardiopulmonary bypass $(\mathrm{CPB})$. The acute ventricular asynchrony and systolic dysfunction generated during this period, far exceed those seen in the setting of chronic heart failure (CHF) treated by CRT. Delayed recovery of myocardial performance following restoration of myocardial flow, referred as "stunning", is a well documented phenomenon, associated to CPB reperfusion [5].

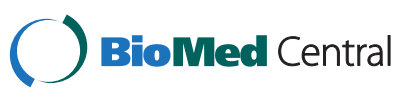

(C) 2012 García Bengochea et al.; licensee BioMed Central Ltd. This is an Open Access article distributed under the terms of the Creative Commons Attribution License (http://creativecommons.org/licenses/by/2.0), which permits unrestricted use, distribution, and reproduction in any medium, provided the original work is properly cited. 
The adverse movement of the interventricular septum toward the right ventricle, during systolic contraction it is another common finding after $\mathrm{CPB}$ [6]. The above mentioned alterations, and a depressed preoperative ventricular function, are often responsible of hemodynamic (HD) instability, which difficult weaning of $\mathrm{CPB}$, requiring inotropic and vasoactive support, electrical stimulation and even mechanical assistance.

Placement of RV temporary epicardial electrodes, is a routine procedure during cardiac surgery to treat bradicardia with low cardiac output $(\mathrm{CO})$ or atrio-ventricular block. This pacing site, usually generates an undesirable cardiac effect, due to the PSM created by the initial RV activation [7]. Cannesson et al. [8] have shown, that acute RA- RVP after CPB, in the absence of right bundle branch block (RBBB), worsens $\mathrm{CO}$.

Nelson et al. [9], have demonstrated that LVP or BiVP can acutely improve systolic function in cases with intraventricular conduction delay, without increasing myocardial oxygen extraction (MV02). This new therapeutic pathway has been investigated by Bakhtiary and co-.authors [10],finding that BiVP was associated with improved LV contractility without rising MV02 compared with atrial pacing This fact may allow to diminish inotropic administration protecting additionally myocardial metabolism. Therefore optimization of temporary stimulation (TS) after CPB,particularly in cases with depressed LV function it must be considered a coadyuvant method for the improvement of $\mathrm{CO}$, which at certain perioperative stages may be crucial.

At present, and despite recent clarifying investigations concerning pacing configurations, stimulation site, perioperative phase and simultaneous adjustments of atrioventricular (AVD) and interventricular delays (VVD) [11-14], there is still absence of clear recomendations to optimized TS. This fact, is mainly due to the above mentioned variables employed in heterogeneous populations and in a changeable and complex scenario.

Our initial experience [15] using biventricular (BiV) dual cathodal stimulation which allows VVD adjustments, promoted the present prospective controlled clinical trial. The aim of this study was to assess the potential hemodynamic benefits of TS, employing routine pacing configurations and sites during the immediate postoperative phase in a wide sample of patients. Improvement of $\mathrm{CO}$, an important short-term parameter, was considered the end point.

\section{Methods}

\section{Patient population}

A total of 50 patients electively submitted to CPB surgery between March 2008 and May 2010 were included in the present study. Institutional ethical committee approval was obtained. All patients gave fully written informed consent. Exclusion criteria were the presence of previous pacemaker, severe tricuspid incompetence in order to maintain the accuracy of thermodilution derived $\mathrm{CO}$ measurements and intracardiac shunt. The development of cardiac arrhythmias in the early post-operative period, requiring antiarrhythmic drugs or postoperative low cardiac output needing mechanical support were also considered an exclusion criteria

Mean age was $67.14 \pm 11.18$ years (range $39-82$ ). Preoperative diagnosis included, isolated valve disease in 31 cases (62\%), isolated coronary artery disease in 15 cases (30\%) and mixed disease (8\%) requiring valve surgery with coronary artery bypass grafting (CABG) (Table 1).

Left bundle branch block (LBBB) was present in 9 patients (18\%) and RBBB in $2(4 \%)$. Left ventricular ejection fraction (LVEF) derived from transthoracic Doppler echocardiography using the Simpson method was preserved (LVEF $\geq 50 \%$ ) in 25 cases (50\%); moderate depression (LVEF $3 \%-49 \%$ ) in 18 cases (36\%), and severe dysfunction (LVEF $<35 \%$ ) in 7 cases $(14 \%)$. Sinus rhythm (SR) was present in $84 \%$ of cases and $16 \%$ were in atrial fibrillation (AF) with depressed LVEF.

Intraoperative patient monitoring included invasive blood pressure and continuous ECG registry. Following general anesthesia and orotracheal intubation, a heparin coated Swan-Ganz catheter (Opti-Q,Abbott Critical Care System, Abbott Laboratories, IL,USA) was placed for hemodynamic management and determinations: pulmonary artery pressures and systemic vascular resistance. The

Table 1 Demographic, preoperative and intraoperative characteristics of the population included in the study

\begin{tabular}{|c|c|}
\hline Number & (n) 50 \\
\hline Male/female & $38 / 12$ \\
\hline Age (years) & $67.14 \pm 11.18$ \\
\hline \multicolumn{2}{|l|}{ LVEF (\%) } \\
\hline$\geq 50 \%$ & 50 \\
\hline $35-49 \%$ & 36 \\
\hline$<35 \%$ & 14 \\
\hline Isolated valve disease (\%) & $62 \%(31)$ \\
\hline Isolated coronary artery disease (\%) & $30 \%[15]$ \\
\hline Mixed valve and coronary disease (\%) & $85[4]$ \\
\hline Sinus rhythm (\%) & 84 \\
\hline Atrial fibrillation (\%) & 16 \\
\hline LBBB (\%) & 18 \\
\hline RBBB (\%) & 4 \\
\hline Median sternotomy approach & $100 \%$ \\
\hline Aortic cross clamp time (min) & $73 \pm 29.5$ \\
\hline Cardiopulmonary bypass time (min) & $91 \pm 21.5$ \\
\hline Warm intermittent cardiopegia & $100 \%$ \\
\hline
\end{tabular}

LVEF: Left ventricular ejection fraction. LBBB: Left bundle branch block. RBBB: Right bundle branch block.

Data are expressed as mean \pm SD. 
catheter was connected to a monitor $(\mathrm{Q} 2 \mathrm{CCO} / \mathrm{SvO} 2$ computer, Abbot Lab, IL,USA) for continuous monitoring of $\mathrm{CO}$ and mixed venous oxygen saturation $(\mathrm{SvO} 2)$. The use of validated automated $\mathrm{CO}$ method allows determinations of rapid change in $\mathrm{CO}$, useful for modifying pacing parameters: atrio-ventricular delay (AVD), interventricular delay (VVD) and pacing configurations. Surgery was performed through a median sternotomy and under standard $\mathrm{CPB}$. After aortic cross clamping, cold hyperkalemic antegrade blood cardioplegia was administered for cardiac arrest and repeated every $20 \mathrm{~min}$. Controlled reperfusion was achieved using a single dose of warm cardioplegia. After completion of the surgical procedure, weaning of $\mathrm{CPB}$ and removal of atrial canulae, epicardial unipolar pacing wires (Streamline 6500; Medtronic, Inc, Minneapolis, Minn. USA) were placed at the right atrial appendage (RA), diaphragmatic surface of the RV (DSRV) and posterobasal LV wall, then passed percutaneously and sutured to the skin at the lower end of the sternotomy incision.

In all cases, basal hemodynamic parameters: $\mathrm{CO}$, systolic, diastolic and mean arterial pressure (MAP), pulmonary artery pressures, $\mathrm{SvO} 2$ and a 12 lead surface electrocardiogram were registered, $1-2 \mathrm{~h}$ after admission to the intensive care unit and once the patient had reached hemodynamic stability. Patients were sedated and mechanical ventilation parameters were held constant during the study. Norepinephrine was administered if required in order to reach MAP of at least $60 \mathrm{mmHg}$. No other inotropic agents were administered during the procedure. Blood pressures were determined as the mean of the values obtained at the end of three consecutive respiratory cycles. During the study, volume administration or intravenous drug infusions were held constant, whitout additional medications. Cases with a post-CPB heart rate $>120$ beats/min were excluded. Stimulation was performed at a rate $10 \%$ superior to the basal rate during $6 \mathrm{~min}$, using the different configurations and parameters. Then discontinued for $10 \mathrm{~min}$ after each period. External temporary dual-chamber generators (model 5345, Medtronic Inc, Minneapolis, Min, USA and ERA 300 Biotronik, SE\&Co, Berlin,Germany) were employed.

In AF cases, for achievement of dual cathodal BiVP with VVD adjustments, an implantable pulse generator, Biotronik Logos D, was used as an external pacemaker. The atrial port of the generator was usually connected to the LV lead and the ventricular port to the RV electrode, using the generator as the positive pole to close the circuit. In patients in SR two configurations were used: a) RA-LV bipolar anocathodal mode (cathode in LV). b) RA-RV bipolar anocathodal mode (cathode in RV)The AVD was modified within a range of 80 to $200 \mathrm{~ms}$, according to the patients heart rate, MAP and
$\mathrm{CO}$ monitoring. In AF patients, three different configurations were used :a) LV bipolar anocathodal (cathode in LV, anode in RV). b) RV bipolar anocathodal (cathode in RV, anode in LV).c) BiVP dual cathodal (cathodes in LV and RV) with adjustable VVD. With QRS $<120 \mathrm{~mm}$ the delays ranged from $+20-40 \mathrm{~ms}$. With a wide QRS > $120 \mathrm{~mm}$, the delays ranged from $0-80 \mathrm{~ms}$. At least 3 settings were used in each study. The highest $\mathrm{CO}$ obtained was considered the optimal.

Echocardiographic assessment was only performed in AF cases. Mitral regurgitation jets were imaged using colour Doppler echocardiography in parasternal longaxis and four chamber view. The maximal regurgitant jets were determined during intrinsic rhythm and with the various pacing configurations in order to calculate the $\mathrm{dP} / \mathrm{dt}$ max as a contractility index. Left ventricular dyssynchrony was assessed using tissue Doppler imaging by transthoracic or transesophageal echo-doppler ultrasound.

Analysis of the whole population was obtained. Several sub-groups were established for comparisons according to: LVEF, type of BBB, basal rhythm and type of surgery. Subjects served as their own control.

Statistical analysis was performed with the Wilcoxon rank sum test for paired data, using SPSS software (SPSS, Inc., Illinois, USA). Due to pairewise comparisons, Bonferroni correction was performed. A p-value of less than 0.05 was considered statistically significant. Continuous data were expressed as mean \pm standard deviation.

\section{Results}

The analysis of the overall population comparing RALVP and RA-RVP modes with basal values showed a significant increase in CO and MAP in favour of RA-LVP, close to $80 \%$ of patients, whereas RA-RV, significantly decreased both parameters (Table 2).

In the subgroup with preserved LVEF, RA-LVP pacing produced a significant increase of $\mathrm{CO}$, although not of MAP. With RA-RVP, a significant decrease of $\mathrm{CO}$ and MAP was noticed (table 3). In the low EF sub-group, the RA-LVP, increased significantly $\mathrm{CO}$ and MAP with increments of $7.5 \%(0.40 \mathrm{l} / \mathrm{m})$ and $7.7 \%$ respectively. (Table 3).

The LBBB subgroup, showed that RA-LVP increased significantly CO and MAP: $7.3 \%(0.43 \mathrm{l} / \mathrm{min})$ and $8.9 \%$ respectively. In contrast, RA-RVP decreased significantly both (Table 4). Also in the subgroup without LBBB, RALVP increased both CO and MAP (Table 4).

In the valve surgery sub-group, RA-LVP, improved significantly $C O(5.14 \pm 1.47 \mathrm{l} / \mathrm{m}$ vs $5.44 .1 .71 \pm \mathrm{l} / \mathrm{m} ; \mathrm{p}<$ $0.05)$ and MAP $(72.6 \pm 4.1 \mathrm{mmHg}$ vs $75.7 \pm 5 \mathrm{mmHg}$; $\mathrm{p}<0.0 .01)$ with regard to basal values. With RA-RVP, CO significantly decreased $(5.14 \pm 1.47 \mathrm{l} / \mathrm{m}$ vs $4.831,43 \pm$ 
Table 2 Analysis of the hemodynamic parameters of the overall population

\begin{tabular}{llll}
\hline $\begin{array}{l}\text { Hemodynamic } \\
\text { parameters }\end{array}$ & Basal & \multicolumn{2}{c}{ Stimulation mode } \\
\cline { 2 - 4 } & & RA-LVP & RA-RVP \\
\hline HR $(\mathrm{bpm})$ & $72,80 \pm 8,60$ & $83,70 \pm 4,22^{* *}$ & $83,74 \pm 4,74^{* *}$ \\
\hline SAP $(\mathrm{mmHg})$ & $107,80 \pm 14,75$ & $111,24 \pm 18,88^{* *}$ & $98,76 \pm 15,08^{* *}$ \\
\hline DAP $(\mathrm{mmHg})$ & $52,64 \pm 7,59$ & $55,50 \pm 8,32^{* *}$ & $49,96 \pm 8,10^{* *}$ \\
\hline MAP $(\mathrm{mmHg})$ & $71,01 \pm 6,2$ & $74,4 \pm 6,8^{* *}$ & $66,4 \pm 6,1^{* *}$ \\
\hline CO (L/min) & $5,30 \pm 1,54$ & $5,61 \pm 1,72^{*}$ & $5,08 \pm 1,60^{* *}$ \\
\hline SV02 (\%) & $69,96 \pm 7,10$ & $69,80 \pm 8,01$ & $68,28 \pm 7,81$
\end{tabular}

RA-LVP: Right atrium-left ventricle. RA-RVP: Right atrium-right ventricle. HR (bpm): Heart rate beats per minute. SAP $(\mathrm{mmHg})$ : Systolic arterial pressure. DAP $(\mathrm{mmHg})$ : Diastolic arterial pressure. MAP $(\mathrm{mmHg})$ : Mean arterial pressure $\mathrm{CO}(\mathrm{L} / \mathrm{min})$ : Cardiac output. SvO2 (\%): Mixed venous oxygen saturation. ${ }^{*} \mathrm{p}<$ $0.05 ; * * 0<0.01$.

Data are expressed as mean $\pm S D$.

$1 / \mathrm{m} ; \mathrm{p}<0.05)$ and also MAP $(72.6 \pm 4.1 \mathrm{mmHg}$ vs $67.8 \pm$ $6.1 \mathrm{mmHg}$; $<0.001$ ).

In the CABG sub-group, only $\mathrm{CO}$ increased significantly with RA-LVP $(5.66 \pm 1.68 \mathrm{l} / \mathrm{m}$ vs $5.99 \pm 1.76 \mathrm{l} / \mathrm{m}$, $\mathrm{p}<0.05)$, whereas RA-RVP significantly decreased CO $(5.66 \pm 1.68 \mathrm{l} / \mathrm{m}$ vs $5.47 \pm 1.97 \mathrm{l} / \mathrm{m} ; \mathrm{p}<0.05)$ and MAP $(69.6 \pm 3.8 \mathrm{mmHg}$ vs $64.3 \pm 4.5 \mathrm{mmHg}, \mathrm{p}<0.001)$ relative to basal values. The combined CABG and valve surgery sub-group, showed an increase of MAP (66.6 \pm $5.2 \mathrm{mmHg}$ vs $71.4 \pm 4.4 \mathrm{mmHg})$ and $\mathrm{CO}(5.20 \pm 1.74 \mathrm{l} / \mathrm{m}$ vs $5.47 \pm 1.83 \mathrm{l} / \mathrm{m}$ ) with RA-LVP and a decline of CO $(5.20 \pm 1.74 \mathrm{l} / \mathrm{m}$ vs $4.77 \pm 1.4 \mathrm{l} / \mathrm{m})$ with RA-RVP, without statistical significance (4 cases only).

In the SR group with RA-LVP, CO significantly increased (5.5\%) and also MAP (Table 5).
In the AF group, LVP and BiVP, yielded a significant increase of CO:8.5\% (0.39 l/min) and 11.6\% (0.53 l/min) respectively, without significant differences between them (Table 6).

No significant chnages in Sv02, were found in the overall population nor in any of the subgroups, except in the AF group, which increased significantly with LVP and BiVP (Table 6). No significant differences in pulmonary artery pressures were observed.

Echocardiographic evaluation of this group, showed lateral wall septal dyssynchrony (SS-PPS delay $>60 \mathrm{~ms}$ ) in all cases. LVP and BIVP produced symmetrical contraction of the LV mid-septal and lateral wall with both pacing modes. The $. \mathrm{dP} / \mathrm{dt}$ max,(Figure 1) increased significantly with both LVP and BiVP, without significant differences between them The highest increments of $\mathrm{dP} / \mathrm{dt}$ max where obtained in cases with the lowest basal values.

\section{Discussion}

Temporary stimulation on the RVDS with epicardial electrodes after CBP is a common practice in cardiac surgery. Different studies, investigating the sites of pacing to optimize CO including: RVP at, apical, diaphragmatic surface, paraseptal and outflow tract; LVP: posterobasal, mid free-wall, apical and paraseptal, have generated controversial results [16-21].

Vaughan et al. [22] performed an extreme search on the subject. They concluded that only 9 of the 13 publications, resulted in significant increases of cardiac index, up to $22 \%$ with BiVP or AR-LVP. Tanaka et al. and others $[18,22,23]$ observed greatest benefits in patients

Table 3 Analysis in patients with preserved left ventricular ejection fraction and depressed left ventricular ejection fraction, including moderate and severe dysfunction

\begin{tabular}{|c|c|c|c|}
\hline \multirow[t]{2}{*}{ Hemodynamic parameters } & \multirow[t]{2}{*}{ Basal } & \multicolumn{2}{|c|}{ Preserved left ventricular function $(n=25)$} \\
\hline & & RA-LVP & RA-RVP \\
\hline $\mathrm{HR}$ (bpm) & $72,80 \pm 8,28$ & $83,88 \pm 4,55^{* *}$ & $84,04 \pm 4,62^{* *}$ \\
\hline $\mathrm{SAP}(\mathrm{mmHg})$ & $111,28 \pm 16,29$ & $109,80 \pm 21,46^{*}$ & $100,32 \pm 16,08^{*}$ \\
\hline $\mathrm{DAP}(\mathrm{mmHg})$ & $57,76 \pm 7,76$ & $56,16 \pm 8,69^{*}$ & $50,96 \pm 9,12^{*}$ \\
\hline MAP $(\mathrm{mmHg})$ & $75,5 \pm 14,2$ & $74,1 \pm 21,1$ & $67,4 \pm 17,6^{*}$ \\
\hline $\mathrm{CO}(\mathrm{L} / \mathrm{min})$ & $5,30 \pm 1,37$ & $5,52 \pm 1,65^{*}$ & $4,93 \pm 1,36^{*}$ \\
\hline \multirow[t]{2}{*}{ SV02 (\%) } & $69,56 \pm 7,62$ & $69,28 \pm 8,46$ & $67,96 \pm 8,72$ \\
\hline & & \multicolumn{2}{|c|}{ Depressed left ventricular function $(n=25)$} \\
\hline $\mathrm{HR}(\mathrm{bpm})$ & $72,80 \pm 8,28$ & $83,60 \pm 4,55^{* *}$ & $83,44 \pm 4,38^{* *}$ \\
\hline $\mathrm{SAP}(\mathrm{mmHg})$ & $104,32 \pm 12,31$ & $112,68 \pm 14,48^{*}$ & $97,20 \pm 14,17^{*}$ \\
\hline $\mathrm{DAP}(\mathrm{mmHg})$ & $50,52 \pm 6,93$ & $54,84 \pm 8,09^{*}$ & $48,96 \pm 6,98^{*}$ \\
\hline MAP $(\mathrm{mmHg})$ & $68,4 \pm 3,7$ & $74,1 \pm 5,9^{* *}$ & $65,7 \pm 4,9^{* *}$ \\
\hline $\mathrm{CO}(\mathrm{L} / \mathrm{min})$ & $5,30 \pm 1,72$ & $5,70 \pm 1,81^{*}$ & $5,11 \pm 1,84^{* *}$ \\
\hline Sv02 (\%) & $70,36 \pm 8,28$ & $70,32 \pm 7,67$ & $68,60 \pm 6,95$ \\
\hline
\end{tabular}

RA-LVP: Right atrium-left ventricle. RA-RVP: Right atrium-right ventricle. HR (bpm): Heart rate beats per minute. SAP (mmHg): Systolic arterial pressure. DAP (mmHg): Diastolic arterial pressure. MAP ( $\mathrm{mmHg})$ : Mean arterial pressure. $\mathrm{CO}(\mathrm{L} / \mathrm{min})$ : Cardiac output. SvO2 (\%): Mixed venous oxygen saturation. ${ }^{*} \mathrm{p}<0.05 ;{ }^{* *} \mathrm{p}<0.01$. Data are expressed as mean $\pm \mathrm{SD}$. 
Table 4 Analysis in the group of patients with and without left bundle branch block

\begin{tabular}{|c|c|c|c|}
\hline \multirow{2}{*}{$\begin{array}{l}\text { Hemodynamic } \\
\text { parameters }\end{array}$} & \multirow[t]{2}{*}{ Basal } & \multicolumn{2}{|c|}{ With LBBB $(n=9)$} \\
\hline & & RA-LVP & RA-RVP \\
\hline $\mathrm{HR}$ (bpm) & $74,33 \pm 7,48$ & $84,22 \pm 3,23^{* *}$ & $84,22 \pm 3,23^{* *}$ \\
\hline SAP $(m m H g)$ & $99,11 \pm 7,38$ & $109,22 \pm 15,25^{*}$ & $89,11 \pm 12,10^{* *}$ \\
\hline $\mathrm{DAP}(\mathrm{mmHg})$ & $51,56 \pm 7,38$ & $55,44 \pm 9,04^{*}$ & $47,33 \pm 5,02^{* *}$ \\
\hline MAP (mmHg) & $67,3 \pm 5,2$ & $73,3 \pm 6,1^{*}$ & $61,3 \pm 4,5^{*}$ \\
\hline $\mathrm{CO}(\mathrm{L} / \mathrm{min})$ & $5,56 \pm 1,81$ & $5,97 \pm 2,09^{* *}$ & $5,23 \pm 1,90^{*}$ \\
\hline \multirow[t]{2}{*}{ Sv02 (\%) } & $68,22 \pm 7,22$ & $69,00 \pm 7,54$ & $67,00 \pm 5,98$ \\
\hline & & \multicolumn{2}{|c|}{ Without LBBB $(n=41)$} \\
\hline $\mathrm{HR}$ (bpm) & $72,46 \pm 8,87$ & $83,63 \pm 4,44^{* *}$ & $83,63 \pm 4,72^{* *}$ \\
\hline SAP $(m m H g)$ & $109,71 \pm 15,88$ & $111,68 \pm 18,90^{*}$ & $100,08 \pm 14,96^{* *}$ \\
\hline DAP $(\mathrm{mmHg})$ & $52,88 \pm 7,70$ & $55,51 \pm 8,27^{*}$ & $50,54 \pm 8,57^{* *}$ \\
\hline MAP (mmHg) & $71,8 \pm 4,3$ & $74,2 \pm 4,8$ & $67,0 \pm 5^{* *}$ \\
\hline $\mathrm{CO}(\mathrm{L} / \mathrm{min})$ & $5,25 \pm 1,49$ & $5,54 \pm 1,67^{*}$ & $4,97 \pm 1,55^{*}$ \\
\hline Sv02 (\%) & $70,34 \pm 7,11$ & $65,95 \pm 8,19$ & $68,56 \pm 8,19$ \\
\hline
\end{tabular}

RA-LVP: Right atrium-left ventricle. RA-RVP: Right atrium-right ventricle. HR (bpm): Heart rate beats per minute. SAP $(\mathrm{mmHg})$ : Systolic arterial pressure. DAP $(\mathrm{mmHg})$ : Diastolic arterial pressure. MAP $(\mathrm{mmHg})$ : Mean arterial pressure. CO (L/min): Cardiac output. SvO2 (\%): Mixed venous oxygen saturation. LBBB: Left bundle branch block. * $p<0.05 ; * * p<0.01$.

Data are expressed as mean \pm SD.

with low EF and wide QRS complex. Whereas others, report no significant hemodynamic improvement with these pacing modes or even no adverse effects with RA-RVP in populations with normal ventricular function [19-21].

The strategy for perioperative optimization, by means of LVP or BiVP using a LV basal cathodal electrode and adequate adjustments of AVD and VVD if feasible, is gaining progressive acceptance, to improve $\mathrm{CO}$ perioperatively, particularly in cases with depressed EF and LBBB $[11,13,18,23]$

In our study, in an heterogeneous population, RA-LVP, LVP or BiVP effectiveness, was validated by MAP and $\mathrm{CO}$ monitoring, proving to be beneficial in almost $80 \%$

Table 5 Hemodynamic parameters in the group of patients with sinus rhythm $(n=42)$

\begin{tabular}{llll}
\hline $\begin{array}{l}\text { Hemodynamic } \\
\text { parameters }\end{array}$ & Basal & \multicolumn{2}{c}{ Stimulation mode } \\
\cline { 2 - 4 } & & RA-LVP & RA-RVP \\
\hline HR $(\mathrm{bpm})$ & $73,74 \pm 8,66$ & $83,93 \pm 4,51^{* *}$ & $83,98 \pm 4,75^{* *}$ \\
\hline $\mathrm{SAP}(\mathrm{mmHg})$ & $106,81 \pm 14,38$ & $108,67 \pm 15,33^{*}$ & $97,38 \pm 14,03^{* *}$ \\
\hline $\mathrm{DAP}(\mathrm{mmHg})$ & $52,36 \pm 7,92$ & $54,14 \pm 7,51^{*}$ & $50,00 \pm 8,32^{* *}$ \\
\hline $\mathrm{MAP}(\mathrm{mmHg})$ & $70,4 \pm 3,1$ & $72,1 \pm 3,4^{* *}$ & $65,8 \pm 4,3^{* *}$ \\
\hline $\mathrm{CO}(\mathrm{L} / \mathrm{min})$ & $5,44 \pm 1,57$ & $5,74 \pm 1,77^{*}$ & $5,16 \pm 1,65^{*}$ \\
\hline SV02 $(\%)$ & $69,74 \pm 6,62$ & $69,17 \pm 7,11$ & $67,83 \pm 7,22$
\end{tabular}

RA-LVP: Right atrium-left ventricle. RA-RVP: Right atrium-right ventricle. HR (bpm): Heart rate beats per minute. SAP ( $\mathrm{mmHg})$ : Systolic arterial pressure. DAP $(\mathrm{mmHg})$ : Diastolic arterial pressure. MAP $(\mathrm{mmHg})$ : Mean arterial pressure. $\mathrm{CO}(\mathrm{L} / \mathrm{min})$ : Cardiac output. SvO2 (\%): Mixed venous oxygen saturation. ${ }^{*} \mathrm{p}<0.05 ; * * \mathrm{p}<0.01$.

Data are expressed as mean \pm SD. of the whole population, with significant improvements of MAP and CO in the low EF and LBBB subgroups, being highest in the AF group with depressed EF. The increments obtained may appear rather modest but simultaneously avoid the adverse effects of RVP. Similar positive results with RA-LVP have been obtained by Flynn et al. [16].

In the average population, RA-RVP decreases $\mathrm{CO}$ and MAP and this effects also occurs in the different subgroups studied. Similar adverse observations have been reported in cases undergoing CABG surgery $[8,18]$. Besides, it has been noticed that with low EF, systolic dyssynchrony with RA-RVP is significantly higher compared with RA-LVP or BiVP [13],except in cases with RBBB [18]. From our study, no conclusions can be reached as there were only two cases with such alteration.

Our investigation, shows a $20 \%$ of non responders. They were tested only by RA-RVP or RA-LVP modes with AVD adjustments. The most delayed site on the inferolateral LV wall was not established by echocardiography and BiVP was not applied in the SR group, lacking a possible optimization of synchronicity with VVD.

In the setting of postoperative $\mathrm{CPB}$, there is very limited experience reported with AF, generally due to the established exclusion criteria. In an acute HD study in CHF, including AF cases, Blanc et al. [24] observed a significant increase of systolic blood pressure with both LVP and BiVP.

Mixed venous oxygen saturation, only showed favourable significant differences, in the group of $\mathrm{AF}$ with $\mathrm{EF}<35 \%$, using LVP or BiVP. Eberhardt el al [17] in CABG patients, did not found differences in $\mathrm{SvO} 2$ among the various pacing modalities. Our results seem to indicate that $\mathrm{SvO} 2$, may not be a suitable parameter to validate the effectiveness of the different postoperative TS modes, when ventricular function is preserved.

Due to the nonexistence of an external triple chamber pacemaker, we employed only in AF cases, a biventricular dual cathodal pacing system [15], which implies two independent activated circuits, with a cathode in each ventricle, allowing VVD adjustments. To our knowledge the present study, using dual cathodal BiVP is the only clinical experience reported, in cases with $\mathrm{AF}$, during the postoperative CPB period.

Few reports provide a precise description of the BiVP configuration used, accomplished either with the split bipole or the dual cathodal split system, but always with the drawback of not been able to adjust the VVD, to maximize the optimization benefit [11,12]. Fernandez et al. (30) questioned the assessment of the potential hemodynamic benefits of TS, based on the fact, that different authors have used distinct terminology for the pacing configurations of left anocathodal system, versus biventricular left cathodal split bipole. 
Table 6 Hemodynamic parameters in the group of patients with atrial fibrillation $(\mathbf{n}=\mathbf{8})$

\begin{tabular}{lllll}
\hline Hemodynamic parameters & Basal & LVP & RVP & BiVP \\
\hline HR $(\mathrm{bpm})$ & $67,88 \pm 6,77$ & $82,75 \pm 2,12^{* *}$ & $82,50 \pm 4,38^{* *}$ & $82,64 \pm 2,16^{* *}$ \\
\hline SAP $(\mathrm{mmHg})$ & $113,00 \pm 16,36$ & $124,75 \pm 26,90^{*}$ & $106,00 \pm 19,21^{* *}$ & $126 \pm 24,89$ \\
\hline DAP $(\mathrm{mmHg})$ & $54,13 \pm 5,74$ & $62,63 \pm 9,18^{*}$ & $49,75 \pm 7,38^{* *}$ & $60,14 \pm 8,16$ \\
\hline MAP $(\mathrm{mmHg})$ & $72,6 \pm 3,5$ & $83,1 \pm 4,2^{*}$ & $68,4 \pm 4^{*}$ & $85,30 \pm 11,31^{*}$ \\
\hline CO $(\mathrm{L} / \mathrm{min})$ & $4,57 \pm 1,19$ & $4,96 \pm 1,30^{*}$ & $4,30 \pm 1,18^{*}$ & $5,10 \pm 1,78^{*}$ \\
\hline Sv02 (\%) & $67,88 \pm 6,77$ & $73,13 \pm 11,75^{*}$ & $70,63 \pm 10,09$ & $74,0 \pm 14,68^{*}$ \\
\hline
\end{tabular}

Stimulation mode.

BiV: Biventricular dual cathodic. RA-LVP: Right atrium-left ventricle. RA-RVP: Right atrium-right ventricle. HR (bpm): Heart rate beats per minute. SAP (mmHg): Systolic arterial pressure. DAP ( $\mathrm{mmHg}$ ): Diastolic arterial pressure. MAP (mmHg): Mean arterial pressure. CO (L/min): Cardiac output. SvO2 (\%): Mixed venous oxygen saturation. ${ }^{*} \mathrm{p}<0.05$; $^{* *} \mathrm{p}<0.01$

Data are expressed as mean \pm SD

Our study,in AF cases with $\mathrm{EF}<35 \%$, both $\mathrm{LVP}$ and BiVP significantly increased MAP and CO, accompanied by significant improvements of $\mathrm{dP} / \mathrm{dt} \max$, without statistical differences between them. Flynn et al. [16] in a subset of five cases of AF submitted to CABG, placing an active lead on the LV posterobasal area, did not observed significant changes in MAP.

A recent study [12] under acute RV and LV failure conditions, has demonstrated using BiVP, that the $\mathrm{dP} / \mathrm{dt}$ max of the failing ventricle, is maximized when interventricular contraction is close to synchronous. During acute ventricular failure, BiVP parameters like LVP site and the correct VVD, can recruit the unstressed ventricle to support function of the failing one by "interventricular assist".

Right acute ventricular failure after $\mathrm{CPB}$ is an important hemodynamic complication difficult to treat effectively.
BiVP with VVD adjustments, could be very helpful in that setting stressing the relevance of this pacing mode.

Wang et al. [11] in a substudy of the BiPACS trial (mean LVEF < 35\%), have reported an increase of $14 \%$ in $\mathrm{CO}$ after AVD optimization compared with the worst value and 7\% mean increase from an AVD of $120 \mathrm{~ms}$. The optimum VVD differed from the nominal value, in 5\% CO improvement. Overall, optimized BiVP resulted in a CO increase of $10 \%$ versus SR.. Schmidt and coworkers [19],pointed out the limitation of not using AVD and VVD optimization with BiVP, after not obtaining any HD improvement in CBPG cases.

These results, further stress the relevance of optimizing AVD and VVD in the perioperative CPB setting, particularly, in cases with preexisting LV dysfunction, at high risk of developing acute low-output state. Nevertheless, the mechanisms by which pacing optimization

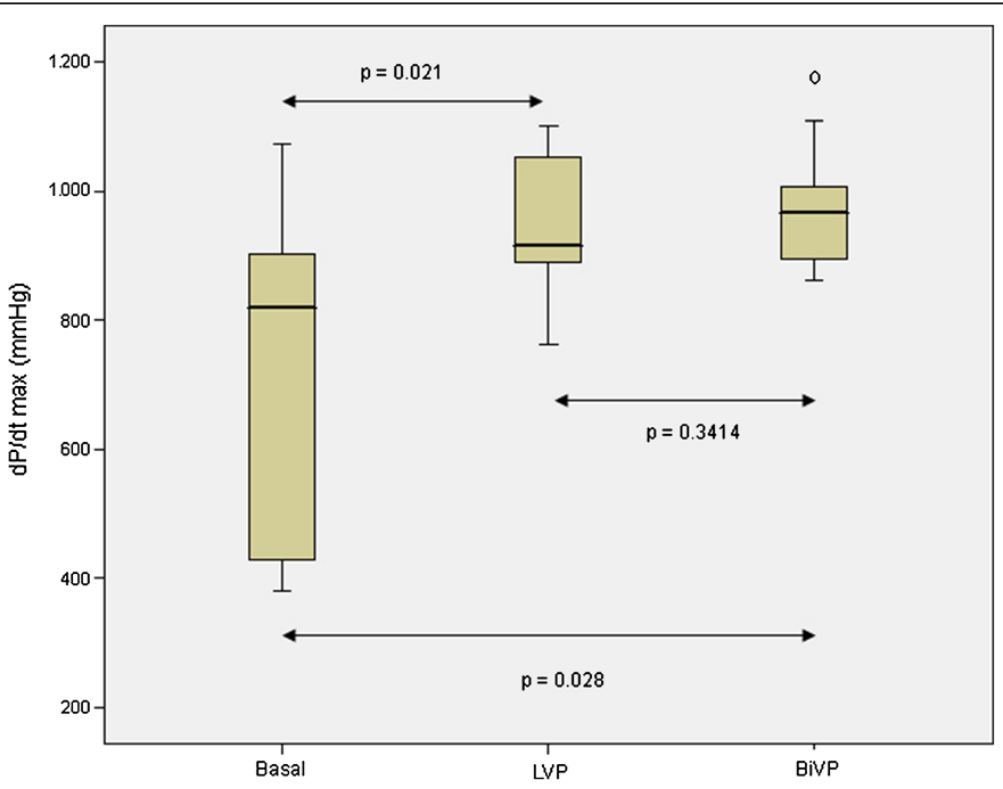

Figure 1 Boxplot representation of $\mathrm{dP} / \mathrm{dt} \max (\mathrm{mmHg} / \mathrm{s})$ values in atrial fibrillation patients using left ventricular pacing (LVP) and biventricular pacing (BiVP) related to basal values. 
improves hemodynamics in this setting, are still not fully defined [14] and require further dedicated studies.

Future investigations using TS to improve cardiac function, will be more feasible using external triple chamber generators with adjustable VVD and should contribute to establish pacing optimization as a routine step of perioperative protocols.

\section{Conclusion}

The present study revealed that for the overall population and the different subgroups analyzed, RA-RVP at the diaphragmatic site induces a decrease of MAP and CO.

Overall, $79 \%$ of the heterogeneous population analyzed, improved CO and MAP using RA-LVP, BiVP or LVP. In the preserved LVEF subgroup, there was an increase in $\mathrm{CO}$ of $4.15 \%$. The benefits increased in the LBBB subgroup reaching 6.6\%. With depressed LVEF there was a further increase up to $7.5 \%$. The highest increase, $11.6 \%$ was obtained with BiVP in AF cases with depressed LVEF.

Non responders to RA-LVP, should be tested by BiVP with VVD adjustments and with the accompaniment of individualized echocardiographic assessment.

\section{Limitations of the study}

Mechanisms underlying the absence of positive response to RA-LVP in $20 \%$ of the sample remain unknown. Individual ecochardiographic assessment in SR cases was not performed and the most delayed activated site on the LV wall not determined. In addition, in these subjects BiVP was not applied.

\section{Competing interests}

The authors declare that they have no competing interests.

\section{Authors' contribution}

JBGB, ALF, and DSC have made substantial contributions to conception and design or acquisition of data, or analysis and interpretation of data.

$J A E, F G$ and JRGJ have been involved in drafting the manuscript and revising it critically.

All authors have given final approval of the version to the be published.

\section{Author details}

${ }^{1}$ Cardiac Surgical Division. Department of Surgery, Hospital Clínico Universitario, 15706, Santiago de Compostela, Spain. ${ }^{2}$ Department of Anesthesiology, Santiago de Compostela, Spain. ${ }^{3}$ Epidemiological Clinic, Santiago de Compostela, Spain. ${ }^{4}$ Department of Cardiology, Hospital Clínico Universitario, 15706Santiago de Compostela, Spain.

Received: 10 June 2012 Accepted: 17 September 2012 Published: 22 October 2012

\section{References}

1. Cazeau S, Leclercq C, Lavergne T, Walker S, Varma C, Linde C, et al: Effects of multisite biventricular pacing in patients with heart failure and intraventricular conduction delay. N Engl J Med 2001, 344:873-880.

2. Auricchio A, Stellbrink C, Sack S, Block M, Vogt J"u, Bakker P: Long-term clinical effect of hemodynamically optimized cardiac resynchronization therapy in patients with heart failure and ventricular conduction delay. J Am Coll Cardiol 2002, 39:2026-2033.

3. Linde C, Leclercq C, Rex C, Garnigue S, Lavergne T, Cazeau S, et al: Long-term benefits of biventricular pacing in congestive heart failure: results from the multisite stimulation in cardiomyopathy (mustic) study. J Am Coll Cardiol 2002, 40(1):111-118.

4. Tse HF, Yu C, Wong KK, Tsang V, Leung YL, Ho WY, et al: Functional abnormalities in patients with permanent right ventricular pacing. the effect of sites of electrical stimulation. J Am Coll Cardiol 2002, 40:1451-1458.

5. Bolli R: Mechanisms of myocardial "stunning". Circulation 1990, 82:723.38.

6. Reynolds HR, Tunick PA, Grossi EA, Dilmanian H, Colvin SB, Kronzon I: Paradoxical septal motion after cardiac surgery: a review of 3292 cases. Clin Cardiol 2007, 30:621-623.

7. Manolis AS: The deleterious consequences of right ventricular apical pacing: time to seek alternarte site pacing. Pacing Clin Electrophysiol 2006, 29(3):298-315.

8. Cannesson M, Farhat F, Scarlata M, Cassar E, Lehot JJ: The impact of atriobiventricular pacing on hemodynamics and left ventricular dyssynchrony compared with atrio-right ventricular pacing alone in the postoperative period of cardiac surgery. I Cardiothorac Vasc Anesth 2009, 23:306-311.

9. Nelson GS, Berger RD, Fetics BJ, Talbot M, Spinelli JC, Hare JM, et al: Left ventricular or biventricular pacing improves cardiac function at diminished energy cost in patients with dilated cardiomyopathy and left bundle-branch block. Circulation 2000, 102:3053-3059.

10. Bakhtiary F, Dogan S, Dzemali O, Ackerman H, Kleine P, Schachinger V, et al: Impact of different pacing modes on left ventricular contractility following cardio pulmonary bypass. Pacing Clin Electrophysiol 2007. 30(9):1083-1090.

11. Wang DY, Richmond ME, Quinn A, Mirani AJ, Rusanov A, Yamalanchi V, et al: Optimized temporary biventricular pacing acutely improves intraoperative cardiac output after weaning from cardiopulmonary bypass: a substudy of a randomized clinical trial. J Thorac Cardiovasc Surg 2011, 141:1002-1008.

12. Quinn TA, Cabreriza SE, Richmond ME, Weinberg AD, Holms JW, Spotnitz HM: Simultaneous variation of ventricular pacing site and timing with biventricular pacing in acute ventricular failure improves function by interventricular assist. Am J Physiol Heart Circ Physiol 2009, 297: $\mathrm{H} 2220-\mathrm{H} 2226$.

13. Hanke T, Misfeld M, Heringlake M, Schreuder JJ, Wiegand UKH, Eberhardt F: The effect of biventricular pacing on cardiac function after weaning from cardiopulmonary bypass in patients with reduced left ventricular function. a pressure-volume loop analysis. J Thorac Cardiovasc Surg 2009, 138:148-156.

14. Spotnitz ME, Wang DY, Quinn TA, Richmond ME, Rusanov A, Johnston T, et al: J Cardiothorac Vasc Anesth 2011, 25:238-242.

15. García-Bengochea JB, Vega M, Fernández A, Rubio J, Sánchez D, Amaro A, et al: Alternativas técnicas de resincronización ventricular epicárdica en la insuficiencia cardiaca. Cir Cardiov 2003, 10:37-44.

16. Flynn MJ, McComb JM, Dark JH: Temporary left ventricular pacing improves hemodynamic performance in patients requiring epicardial pacing post cardiac surgery. Eur I Cardiothorac Surg 2005, 28:250-253.

17. Eberhardt F, Heringlake M, Massalme MS, Dyllus A, Misfeld M, Sievers HH, et al: The effect of biventricular pacing after coronary artery bypass grafting: A prospective randomized trial of different pacing modes in patients with reduced left ventricular function. J Thorac Cardiovasc Surg 2009, 137:1461-1467.

18. Weisse U, Isgro F, Werling C, Lehmann A, Saggau W: Impact of atrio-biventricular pacing to poor left ventricular function after CABG. Thorac Cardiovasc Surg 2002, 50:131-135.

19. Schmidt C, Frielingsdorf J, Debrunner M, Tabacoli R, Genoni M, Straumann E, et al: Acute biventricular pacing after cardiac surgery has no influence on regional and global left ventricular systolic function. Europace 2007, 9:432-436.

20. Evonich RF, Stephens JC, Mehri W, Dukkipati S, Tepe N, Shannon F, et al: The role of temporary biventricular pacing in the cardiac surgical patient with severely reduced left ventricular systolic function. $J$ Thorac Cardiovasc Surg 2008, 136:915-921.

21. Healy DG, Hargrove M, Doddakulla K, Hinchion J, OıDonnell A, Aherne T: Impact of patient modality and biventricular pacing on cardiac output 
and coronary coronary flow in the post-cardiothomy patient. Interact Cardiovasc Thorac Surg 2008, 7:805-808.

22. Vaughan $P$, Vhatti F, Hunter S, Dunning J: Does biventricular pacing provide a superior cardiac output compared to univentricular pacing wires after cardiac surgery? Interact Cardiovasc Thorac Surg 2009, 8:673-678.

23. Dzemali O, Bakhtiary F, Israel CW, Ackermann H, Mortiz A, Keline P: Impact of different pacing modes on left ventricular function following cardiopulmonary bypass. Thorac Cardiovasc Surg 2008, 56:87-92.

24. Blanc JJ, Etienne Y, Gillard M, Mansourati J, Munier S, Boschat J, et al: Evaluation of different ventricular pacing sites in patients with severe heart failure: Results of an acute hemodynamic study. Circulation 1997, 96:3273-3277.

25. Fernández AL, García-Bengochea JB, Sánchez D, Alvarez J: Temporary left ventricular pacing after cardiac surgery. Eur I Cardiothorac Surg 2006, 29:633-634.

doi:10.1186/1749-8090-7-113

Cite this article as: García-Bengochea et al.: Temporary epicardial left ventricular and biventricular pacing improves cardiac output after cardiopulmonary bypass. Journal of Cardiothoracic Surgery 2012 7:113.

\section{Submit your next manuscript to BioMed Central and take full advantage of:}

- Convenient online submission

- Thorough peer review

- No space constraints or color figure charges

- Immediate publication on acceptance

- Inclusion in PubMed, CAS, Scopus and Google Scholar

- Research which is freely available for redistribution 